\title{
Contributions to Keep the Atmosphere Balanced: How a Magnetic Minimizer of Emissions from Mobile Sources Should Be Designed
}

\author{
Raul Guerrero Torres ${ }^{1}$, Mehrab Mehrvar ${ }^{2}$ \\ ${ }^{1}$ Faculty of Engineering, University of Cartagena, Cartagena de Indias, Colombia, E-mail: \\ rguerrerotores1@unicartagena.edu.co \\ ${ }^{2}$ Department of Chemical Engineering, Ryerson University, 350 Victoria Street, Toronto, ON, Canada M5B 2K3 E-mail: \\ mmehrvar@ryerson.ca
}

\begin{abstract}
This paper is the first of an integrated set of documents intended to contribute to reduce air pollution controlling $\mathrm{CO} 2$ emissions and consequently helping to keep Carbon Cycle Balance. It is a selfless, committed and responsible contribution with technical information and experiences of 11 years of work with magnetic minimizers of emissions from mobile sources, which could facilitate synergistic work, by integrating facts whose importance could be going unnoticed, rather than favoring the environmental controversy. The main goal of this first paper is to disseminate a system of procedures to design a magnetic efficient and balanced minimizer of gases emissions from mobile sources. Such a minimizer must allow to satisfy the commitments made by most countries in the world to strengthen their global response to the threat of climate change, especially the Paris Agreement signed in April of 2016 by 195 countries engaged in an internationally coordinated effort to tackle climate change, by controlling global warming. The system of Procedures is the result of several years of experimental work and is supported by comparisons of Single Day Tests results on cars, without a minimizer and then after installing it, obtained in Colombia's ADC, in 2008 with a magnetic minimizer with hydraulic pretreatment and in 2018 with a magnetic minimizer without pre-treatment, using standard gasoline. When increases of $\mathrm{CO} 2 \mathrm{emissions}$, for 3 tested cars in 2008 were compared with the correspondent $0.7 \%$ increase of the car, tested in 2018, this was found lower, in factors of 3.1, 5 and 2.1. With the minimizer without pre-treatment installed in this car, emissions reductions of $68.4 \%$ in $\mathrm{CO}$ and $12.5 \%$ in $\mathrm{HC}$, meeting the standards, were found. This fact opens the option of designing a magnetic efficient and balanced minimizer; reducing $\mathrm{CO}$ and $\mathrm{HC}$ emissions controlling $\mathrm{CO} 2$ emissions, helping transport sector decarbonization and meeting international commitments.
\end{abstract}

Keywords: Environmental Controversy, Paris Agreement, ADC, Magnetic Efficient Balanced Minimizer.

\section{Introduction}

\subsection{The Atmosphere in Balance}

Atmosphere in balance means that it is in equilibrium. In Physics, the requirements for a body to be in equilibrium are: all forces and all torques are balanced. Other Types of equilibrium are: thermal, of nuclides, in nuclear physics [1], and chemical, among others, all with balanced actions implying no change in a characterizing condition; velocity, number and nuclides concentration, chemical activities, etc. The definition of equilibrium by Webster Dictionary: a state of static or dynamic balance between opposing forces or actions [2] is then proper. However, it is not the case for the atmosphere, acted upon harmonizing processes to keep it balanced. The balance of the earth-atmosphere system and, as a result, the continuity of life, depend on a set of interacting conditions: atmospheric, geophysical, magnetic, climatic, and natural cycles; of water, carbon-oxygen, nitrogen, among others. Therefore, the earth is in a stable but very sensitive balance. Although the planet is kept in thermal equilibrium due to the atmosphere-ocean circulation, great care must be taken with the recycling of materials of the interacting atmosphere with land and ocean; local anthropogenic changes could cause global changes that could unbalance the planet changing it from stable to unstable equilibrium [1]. Typical case known is the increase in sea level due to melting of polar ice caps.

\subsubsection{Limited $\mathrm{CO}$ and $\mathrm{HC}$ Reductions Control $\mathrm{CO} 2$ and Favor Carbon Cycle Balance}

The loss of the atmospheric balance, could bring about the imbalance of the Earth-Atmosphere system, with changes in climate that could affect the continuity of life on earth, in few decades if no action is taken. The atmosphere of the earth is mainly composed of $78 \%$ of N, 21\% O and 1\% of other gases; Argon 0.934\% and CO2 0.036\%. Carbon dioxide is a greenhouse gas that allows solar radiation to pass through the atmosphere but prevents all heat from being reflected 
outwards. In this way, thermal conditions suitable for life with an average temperature of $15^{\circ} \mathrm{C}$ occur on the earth's surface. This produces a natural greenhouse effect without which, life would not be possible. However, if carbon dioxide emissions sent to the atmosphere are continuously increased by the use of fossil fuels from mobile sources or other human activity, solar radiation continues to enter, but it is increasingly difficult to dissipate heat to space and the Earth heats up progressively, increasing the natural greenhouse effect. Considering the earth as a self-regulating system that behaves as if it were alive [3], additional $\mathrm{CO} 2$ emissions from human activities could upset the natural balance of the carbon cycle [4], interrupting the harmony of the Earth-Atmosphere system and consequently, endangering the continuity of life in the earth itself. We see then that $\mathrm{CO} 2$ appears as an unbalancing factor. If combustion of a given fossil fuel in mobile sources were ideal, only $\mathrm{H} 2 \mathrm{O}$ and $\mathrm{CO} 2$ would occur, and $\mathrm{CO} 2$ emissions concentration would be maximum. If combustion of the given fuel is incomplete $\mathrm{CO}, \mathrm{HC}$, other pollutants and $\mathrm{CO} 2$ emissions occur. Reductions of $\mathrm{CO}$ and $\mathrm{HC}$ emissions concentrations, generally imply increase in $\mathrm{CO} 2$ emissions concentrations. This means that $\mathrm{CO}$ and $\mathrm{HC}$ emissions must not be reduced at will. Reductions must be limited to corresponding maximum $\mathrm{CO} 2$ emissions concentrations meeting the international commitments. In this article is shown through emission tests results obtained in 2 cars, in a CDA in Cartagena de Indias, Colombia, with 2 different minimizers, using standard gasoline RON 87, that it is possible to control $\mathrm{CO} 2$ emissions, minimizing $\mathrm{CO}$ and $\mathrm{HC}$ reductions fulfilling the standards. A large number of measurements with different vehicles and fuels are required to generalize the use of (MEB) minimizers to all types of vehicles.

\subsubsection{Climate Change is an Interdisciplinary Scientific Problem. So, Should Be Treated}

Following up the previous ideas, a pathway to face the current Global Warming-Climate Change threat, could be through the concept of balance; beginning with a first stage of formally regulated Global reduction of $\mathrm{CO}$ and $\mathrm{HC}$ from mobile and other sources. This way of facing the Climate Change threat, could facilitate synergistic work, changing positions and activities, to some extent, extreme and irreconcilable and currently hindering each other, to positive actions towards a solution. So far, it has not been possible that environmental controversy comes to an end, despite the great effort made by the researchers in both sides. A very complex physics problem of a general nature, as Climate Change, demands integration of several advanced fields of physics and of course high-level mathematics to be formulated and solved. [5] This would be the second stage in the path to solve the Climate change problem, beyond PDEs [6], models and simulations, as well as the immense number of temperature measurements used to solve the Climate Change problem, that work to some extent but that have not been enough to find a solution. The balance condition of the living planet could be formulated, mathematically, within the Non-Linear Functional Analysis, as a functional, where its functions of time, position and speed would be the interacting elements that compound the Earth-Atmosphere System, as result of an interdisciplinary work of specialists in the field of Earth Sciences, physics and mathematics. Otherwise a complete and definitive solution is unlikely.

\section{Motivation and Supports of This Contribution}

The greatest error of all the rest is the mistaking or misplacing of the last or farthest end of knowledge: for men have entered into a desire of learning and knowledge, sometimes upon a natural curiosity and inquisitive appetite; sometimes to entertain their minds with variety and delight; sometimes for ornament and reputation; and sometimes to enable them to victory of wit and contradiction; and most times for lucre and profession; and seldom sincerely to give a true account of their gift of reason, to the benefit and use of men: as if there were sought in knowledge a couch whereupon to rest a searching and restless spirit; (...) or a tower of state, for a proud mind to raise itself upon; or a fort or commanding ground, for strife and contention; or a shop, for profit or sale; and not a rich storehouse, for the glory of the Creator and the relief of man's estate [7].

2.1 After eleven years devoted to studying and experiencing with magnetic minimizers of emissions from mobile sources; testing them in vehicles to prove that really work, a key idea was finally internalized: to provide a true help, any economic interest or personal benefit must be released from our minds. This true understanding, consistent with the previous quote of the English philosopher Francis Bacon is the root of this new motivation. Now, our heart is unobstructed and the joy of serving replaces the tension, due to personal interest, unleashing our inner potentialities to act in favor of the 
purity of our contributions that we believe are going to be somehow useful to help to reduce Air Pollution and Global Warming.

2.2 After 10 years, Global Warming and Air Pollution keep worsening. News from authorized sources are bad: Global carbon emissions are expected to hit an all-time high in 2019, scientists say, smashing a previous record set in 2018 [8] State of Global Air 2019: Air pollution a significant risk factor. [9]

2.3 The warnings made by experts and by authorized organizations such as WHO, UN, among others, and groups such as the IPCC, based on studies on the past, present and projections of global air pollution and warming confirmed by the alarming deterioration of ecosystems in recent decades and the warnings of spiritual and religious leaders, insisting on our obligation to conserve the environment. [10]

2.4. The aim to decarbonize transport and reduce air pollution agreed virtually by all countries and, consequently, the urgency of controlling $\mathrm{CO}$ and $\mathrm{HC}$ reductions, when using magnetic minimizers.

2.5. The analysis of emissions tests results that are shown in 2 tables presented later in this article.

\section{Justification}

Within the context of the environmental protection we consider very important to justify the system of procedures to design a MEB minimizer, presenting a short but concrete information about the current status and evolution of air pollution and global warming, the environmental impact of Mobile Sources, and the current status and evolution of magnetic minimizers of emissions from mobile sources. The first two correspond to information from WHO, NASA, EPA, IPCC, among others authorized institutions and groups. The third correspond to parts of our previous papers presented to RTESE'17 and RTESE'18 pertinent to being re-cited. [11] [12] [13], to our experiences and new analyzes and conclusions.

\subsection{State and Evolution of Air Pollution 3.1.1 Air Pollution.}

Air pollution is the contamination of indoor or outdoor air by a range of gasses and solids, key health-harmful pollutants; PM2.5, PM10, CO, HC, O3, BC, SO2, NOx, that modify its natural characteristics. [14]

\subsubsection{Main Current State Facts of Air Pollution}

Environmental regulations in developed countries have reduced the individual vehicle's emission. However, this has been offset by an increase in the number of vehicles, and increased use of each vehicle. Some pathways to reduce the carbon emissions of road vehicles considerably have been studied.- Energy use and emissions vary largely between modes, causing environmentalists to call for a transition from air and road to rail and human-powered transport, and increase transport energy efficiency. [15]

The health impact of transport emissions is also a concern. A recent survey of the studies on the effect of traffic emissions on pregnancy outcomes has linked exposure to emissions to adverse effects on gestational duration and possibly intrauterine growth. [16] According to WHO air pollution is among WHO's10 threats to global health. [17]

\subsubsection{Projections of Air Pollution}

Extensive information about air pollution projection may be found through WHO, EPA and others important institutions web pages. [18] However, it is enough to highlight two of most important declarations as follows: 1. Due to continuing urbanization and expansion of urban areas, an increasing share of the population is likely to be exposed to elevated levels of traffic-related pollutants, in spite of the general decrease in overall air pollution levels. Also, exposure to traffic-related air pollutants is probably increasing, as a result of the increasing share of passenger vehicles in commuting and the increasing amount of time that vehicles spend in congested traffic on high-volume roads. In urban areas, congestion and the large number of short trips under cold-start conditions have offset the decrease in emissions per vehicle. [19]

2. In coming decades, road transport is likely to remain significant contributor to air pollution in cities. [20]. 


\subsection{State and Evolution of Global Warming \\ 3.2.1. Climate Change and Global Warming.}

Climate can be described as the average weather over a period of time. Climate change means a significant change in the measures of climate, such as temperature, rainfall, or wind, lasting for an extended period of decades or longer. The Earth's climate has changed many times during the planet's history, with events ranging from ice ages to long periods of warmth. What is different about this period of the earth's history is that human activities are significantly contributing to natural climate change through our emissions of greenhouse gases. This interference is resulting in increased air and ocean temperatures, drought, melting ice and snow, rising sea levels, increased rainfall, flooding and other influences. Climate Change is the sum total impact of several natural and human-made factors.

Global warming is a long-term rise in the average temperature of the Earth's Climate System caused by Greenhouse gases (GHGs) emissions such as carbon dioxide $\left(\mathrm{CO}_{2}\right)$, methane $\left(\mathrm{CH}_{4}\right)$, Nitrous oxide $\left(\mathrm{N}_{2} \mathrm{O}\right)$ and Fluorinated gases that warm the Earth by absorbing energy and slowing the rate at which the energy escapes to space; They act like a blanket insulating the Earth. It is a feature of Climate Change characterized by temperature measurements and by multiple effects of the warming. In the Climate Change context, the term usually refers to the mainly human-caused observed warming since pre-industrial times and its projected continuation, though there were also much earlier periods of global warming. Many of the observed warming changes since the $1950 \mathrm{~s}$ are unprecedented in the instrumental temperature record and in historical and paleoclimate proxy records of climate change over thousands to millions of years.

\subsubsection{Projections on Global Warming}

Projection on Global warming is found in NASA, NOAA, IPCC and others important institutions web pages. However, it is enough to highlight the most important declarations as follows:

The temperature of the earth in May 2018 exceeded the average of the last century. [21]

For 400 Months in A Row, the Earth Has Been Warmer Than 20th Century Average. [22]

\subsection{Environmental impact of Mobile Sources \\ 3.2.2.1 Mobile Sources.}

The term Mobile Sources is used to denote motorized vehicles, airplanes, locomotives, and other engines and equipment that can move from one location to another. There are a significant number of different mobile sources of air pollution, some contributing more to air pollution than others. Due to the large number of sources and their ability to move from one location to another, Mobile Sources are regulated differently from stationary sources. Pollutants from mobile sources contribute to environmental degradation and have negative effects on human health. EPA differentiates between mobile sources by classifying them as either on-road vehicles or non-road vehicles, often subject to different regulations. On Road sources: Cars, Light Duty and Heavy-Duty Trucks, Buses and Motorbikes. Non-road sources: Aircraft, Motorboats (Diesel/Gasoline) Locomotives and Construction Equipment. [23]

\subsubsection{Air Pollution from Mobile Sources [24]}

Major Regulated Pollutants from Mobile Sources: Nitrogen Oxides (NOx), Carbon Monoxide (CO) Particulate Material In Suspension, Lead (Pb), Sulphur Dioxide (SO2). [25] Long and short term exposure to these air suspended Pollutants has a different toxicological impact on humans including respiratory and cardiovascular diseases, neuropsychiatric complications, eyes irritation and long-term chronic diseases such as cancer. Several reports reveal the link between exposure to poor air quality and increasing rate of mortality due to cardiovascular and respiratory diseases. Air pollution is considered as the major environmental risk factor in the incidence of some diseases such as asthma, lung cancer, ventricular hypertrophy, Alzheimer's and Parkinson's diseases, autism, retinopathy, fetal growth, and low birth weight [23].CO2 does not directly attack human health, but it is a GHG that contributes to global warming. [26] 
It is then summarized that the environmental impact of Mobile Sources is significant because transport is a major user of energy and burns most of the world petroleum. This creates air pollution, due to the aforementioned emissions. On the other hand, is a significant contributor to global warming through emission of carbon dioxide. These declarations are supported by conclusions from authorized institutions and groups summarized in several statements, as follows:

Within the transport sector, on road transport is the largest contributor to global warming; about $28 \%$ of global GHG emissions, in 2016 were attributed to the transport sector. Transport emits $65 \%$ of $\mathrm{CO}_{2}$, the most important greenhouse gas (GHG). [27] If global warming crosses the safety threshold of $2^{\circ} \mathrm{C}$ then the consequences could be anywhere between bad and catastrophic (Intergovernmental Panel on Climate Change, IPCC, 2014). For the world to stay within a $2^{\circ} \mathrm{c}$ increase in average temperature the transport sector needs to be decarbonized. [28]

\subsection{Evolution of Magnetic Minimizers of Emissions from Mobile Sources [11] [12][13]}

There should be no doubt that it is possible to reduce air pollution considerably via magnetic minimizers, if most of its entrepreneurs instead of struggling to implement its own devices, often designed in an intricate way, or empirically constructed and having as main purpose, particular economic interests, they would present formal proposals for their optimal design and formal control of the implementation to authorized international environmental institutions, with participation of universities and private entrepreneurs. It is too complicated for an entrepreneur to effectively implement a minimizer satisfying the changing conditions of its environment, ruled mainly by technological development and economic interest, without the support of governments or authorized international environmental institutions. The large-scale implementation of magnetic emission reducers has not been successful, in terms of the solution of air pollution because economic interest has prevailed over the urgency to protect the planet. In most countries of the world, at least one magnetic or other device has been built, oriented towards saving fuel. The implementation, on a large scale of an efficient magnetic minimizer, whose main purpose is economical cannot last. A short time after its entrepreneurs have become rich, environmental demands exceed the devices performance, their updating become increasingly expensive and complicated and therefore will soon fall into obsolescence, as has happened with most devices previously accredited but without sufficient theoretical support for face and overcome the changes that technological development demands. The design of an efficient magnetic device is not simple; Quantum Mechanics [29], Advanced Fluid Mechanics, Chemistry, Computer Sciences, Physical-Mathematical modelling, among others, largely support its design and construction. Therefore, it is essential that the implementation of these devices be in hands of expert people with theoretical and practical knowledge on the subject and conscious that reduction of air pollutants and $\mathrm{CO} 2$ to stable innocuous concentrations before there may be catastrophic consequences for the planet is possible.

\section{General Objective}

The main goal of this paper is to present, a system of procedures to design a magnetic efficient and balanced, MEB, minimizer of gases emissions from mobile sources; efficient to reduce $\mathrm{CO}$ and $\mathrm{HC}$ emissions to concentrations below the standards and allowing $\mathrm{CO} 2$ emissions, meeting the international commitments. The tests emissions results obtained with two different magnetic devices support the general objective.

\section{Procedures to Design a Magnetic Efficient Balanced Minimizer of Emissions}

1. Project the values of gas emissions fulfilling standard limits for the type and model of the test vehicle.

2. Design the prototype that will be used for emissions tests and build it with right materials and dimensions.

The equations are shown, as follows:

\subsection{Equations [1] [29]}

$$
\begin{aligned}
& \mu_{B}=\frac{B^{2}}{2 \mu} \\
& \mu_{B}=\frac{U_{B}}{V}
\end{aligned}
$$




$$
\begin{aligned}
U_{B} & =N_{0} U_{H} \\
U_{H} & =F(B)
\end{aligned}
$$

Equation 1 relates the magnetic field energy density $\mu_{B}$, with the magnetic induction $\mathrm{B}$ and the magnetic permeability of fuel $\mu$. Equation 2 relates $\mu_{B}$ with volume $V$ and $U_{B}$; the total energy provided by the magnetic field to optimize the hydrocarbon molecules, within the volume $V$ of fuel comprised between the magnets, changing them from the low energy state to the maximum energy state.

Equation 3 expresses total energy $U_{B}$ in terms of Avogadro Number and energy $U_{H}$ provided to a hydrogen atom. Equation 4 expresses hydrogen atom energy as function of the magnetic induction $B$ of the magnets.

3. Perform Single Day Tests for the chosen source. As follows: 2 trials on the same day, without the prototype and with the prototype installed after traveling from 5 to $7 \mathrm{~km}$.

4. Compare the results obtained with and without the prototype with the projected ones.

This comparison allows to know how efficient is the prototype to meet the projected values and how much improves the emissions in the test vehicle. If the tests are successful the design is ready and the unit can be built with the proper commercial magnetic induction. Otherwise the magnetic induction has to be adjusted.

5. Increase the Magnetic induction of the prototype, if necessary, to the nearest commercial value and perform new one-day tests.

If the result of these new tests is satisfactory, the value of the magnetic induction of is adequate, the finished design has been completed and the device can be built. If not, magnetic induction has to be adjusted.

6. Decrease magnetic induction to the value of the nearest commercial magnet and new single-day tests are performed. If tests are satisfactory the value of magnetic induction of the magnets is adequate, the finished design has been completed and the device can be built If it is not satisfactory, Periodic Tests, every 7 days, extended to one month, with the device installed will be made.

7. Final Periodic Tests, if necessary.

If the periodic tests are satisfactory, the design is finished and the device can be built. if it is not satisfactory, new periodic tests will be performed. If they are not, a new vehicle of the same type will be used and the same procedure will be followed. If the drawbacks persist, the magnetic induction will be recalculated with the greatest precision and noncommercial magnets will be requested as close as possible to the calculated theoretical value and test would be performed in the same order.

\section{Measurements}

\subsection{Measurements 2018}

A car Hyundai Model 2012 was tested, with two Single Day Tests; without and with a magnetic prototype without pre-treatment. Carbon monoxide (CO) and hydrocarbons (HC) emissions results were obtained, under NTC 5375, from an ADC gas analyzer in the city of Cartagena, Colombia, using standard gasoline.

\subsection{8 [11] Measurements.}

Five cars were tested with two Single Day Tests; without the РРтм device [13] and with the device installed. Only tests for 3 cars are considered. Carbon monoxide (CO) and hydrocarbons (HC) emissions results were obtained from an ADC gas analyzer in the city of Cartagena, Colombia, using standard gasoline.

\section{Tests Results}

7.1 Units Used for Tests

7.1.1 PP Unit [11] [13] Built in San Francisco, California USA by Henry Guerrero (Fig. 1a)

\subsubsection{Magnetic Unit (Prototype) Without Hydraulic Pre-treatment System (Fig. 1b)}

A prototype built by professor Raúl Guerrero, based on theoretical knowledge [1] [29] and experience. [11] [12] [13] It includes a pair of $\mathrm{NdFeB}$ permanent magnets, with a proper magnetic induction $\mathrm{B}$ to provide enough energy to enhance 
combustion. They are bonded to Tivar1000 [30] sheets with adequate thermal, mechanical and electrical properties, mounted symmetrically on the fuel hose and joined to it using adequate plastic fasteners Fig.1b It should be installed as close as possible to the injection of fuel or to carburetor to get good results.
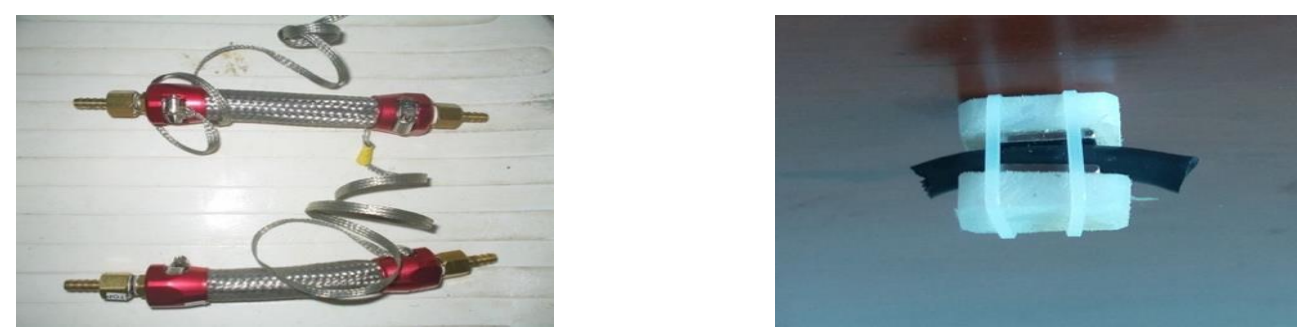

Fig. 1. The actual demonstration of two types of constructed units, a) device used for 2008 tests and b) unit used for 2018 tests

2018 and 2008 Single Day Tests results were arranged according to tables 1 and 2 respectively.

Table 1. Results of Single Day Tests

Using Magnetic unit (Prototype) In a Hyundai Car

\begin{tabular}{|c|c|c|}
\hline \multirow{2}{*}{ Emissions } & \multicolumn{2}{|c|}{ Hyundai Model 2012} \\
\cline { 2 - 3 } & Initial & Final \\
\hline $\mathrm{HC}((\mathrm{PPM})$ & 24 & 21 \\
\hline $\mathrm{CO} 2(\%)$ & 14.1 & 14.2 \\
\hline $\mathrm{CO}(\%)$ & 0.19 & 0.06 \\
\hline $\mathrm{O} 2(\%)$ & 0.31 & 0.31 \\
\hline Drive $(\mathrm{Km})$ & 0 & 6 \\
\hline Mileage $(\mathrm{Km})$ & 70000 & 70006 \\
\hline
\end{tabular}

Table 2. Results of Single Day Tests Using PP Device In 3 Different Cars ${ }^{[2]}$

\begin{tabular}{|c|c|c|c|c|c|c|}
\hline \multirow[b]{2}{*}{ ns } & \multicolumn{2}{|c|}{$\begin{array}{l}\text { Renault Symbol } \\
2005\end{array}$} & \multicolumn{2}{|c|}{$\begin{array}{l}\text { Hyundai } \\
2006\end{array}$} & \multicolumn{2}{|c|}{$\begin{array}{l}\text { Hyundai } \\
2001\end{array}$} \\
\hline & $\begin{array}{l}\text { Initi } \\
\text { al }\end{array}$ & $\begin{array}{l}\text { Fina } \\
1\end{array}$ & $\begin{array}{l}\text { Ini } \\
\text { tial }\end{array}$ & $\begin{array}{c}\mathrm{Fi} \\
\text { nal }\end{array}$ & $\begin{array}{l}\text { Ini } \\
\text { tial }\end{array}$ & $\begin{array}{c}\mathrm{Fi} \\
\text { nal }\end{array}$ \\
\hline $\begin{array}{l}\mathrm{HC}(\mathrm{PP} \\
\mathrm{M})\end{array}$ & 268 & 63 & $3^{23}$ & 60 & $4^{23}$ & 65 \\
\hline $\mathrm{CO} 2(\%)$ & 13.4 & 13.7 & .14 & $.6^{14}$ & $.8^{13}$ & 14 \\
\hline $\mathrm{CO}((\%)$ & 0.15 & 0 & $5^{0 .}$ & $18^{0 .}$ & 410. & $2^{0 .}$ \\
\hline $\mathrm{O} 2(\%)$ & 0.7 & 0.4 & $69^{0 .}$ & $24^{0 .}$ & $98^{0 .}$ & $34^{0 .}$ \\
\hline $\begin{array}{l}\begin{array}{l}\text { Drive }(\mathrm{k} \\
\mathrm{m})\end{array} \\
\end{array}$ & 0 & 6 & 0 & 6 & 0 & 6 \\
\hline Mileage (km) & $\begin{array}{r}535 \\
261\end{array}$ & $\begin{array}{r}535 \\
267\end{array}$ & $\begin{aligned} 26 \\
9268\end{aligned}$ & $\begin{aligned} 26 \\
9274\end{aligned}$ & $536^{86}$ & $542^{86}$ \\
\hline
\end{tabular}




\section{Conclusion}

According to the analysis of the results from Table 1 it is found that the new unit allows to meet the international standards for $\mathrm{CO}$ and $\mathrm{HC}$ emissions, with respective reductions of $68.4 \%$ and $12.5 \%$ for Single Day Tests. When increases of $\mathrm{CO} 2$ emissions concentrations for the 3 cars in Table 2 were compared with the correspondent $0.7 \%$ of car from Table 1 , this increase was found lower, in factors of 3.1, 5 and 2.1. Consequently, it is concluded that the prototype is an efficient and balanced magnetic minimizer (MEB); it reduces $\mathrm{CO}$ and $\mathrm{HC}$ emissions to concentrations below the standards, allowing minimum $\mathrm{CO} 2$, meeting the international commitments to reduce Global Warming. From table 1 it is concluded that a precise calculation of magnetic induction is crucial. Despite the good results obtained, enough tests with different vehicles and fuels must be done using well designed prototypes. Analyses of Tables 1-2 support the presented set of design procedures.

\subsection{Suggestion to the Implementation of a Policy for Transport Sector Decarbonization.}

The fact that $\mathrm{CO}$ and $\mathrm{HC}$ cannot reduced at will without increasing $\mathrm{CO} 2$ emissions beyond the international commitments, suggests regulations policies for limiting reductions of $\mathrm{CO}$ and $\mathrm{HC}$ emissions from transport sector, when using any minimizer device or procedure. This would make easier the global reduction of $\mathrm{CO} 2$ emissions concentrations and help transport sector decarbonization. It is emphasized that regulations are not about maximum standards limits of $\mathrm{CO}, \mathrm{HC}$ and other pollutants concentrations. They are about maximum allowed reductions of $\mathrm{CO}$, $\mathrm{HC}$ and other pollutants emissions concentrations, if MEB minimizers or any other device to abate pollutants is used. This could allow synergistic actions that would help, even more, to control $\mathrm{CO} 2$ and help to stop the environmental controversy hindrance. In a next paper, reflections suggesting a policy for implementing global use of MEBs will be made.

\section{Acknowledgements}

Authors would like to recognize the support of Ryerson University and Universidad de Cartagena through professors M. Mehrvar and R. Galeano, from Chemical Engineering and Math’s Department respectively.

\section{References}

[1] D. H. R. R. Jearl Walker, Fundamentals of Physics 10th Edition, Hoboken: John Wiley \& Sons, Inc., 2014, pp. 327$329,889$.

[2] Merriam-Webster's School Dictionary, Webster's New Enciclopedic Dictionary, New York: Black Dog \& LEVENTHAL PUBLISHERS INC, 1993.

[3] J. Lovelock, The Revenge of Gaia, London: Penguin Books, 2007.

[4] J. Cook, "How do human CO2 emissions compare to natural CO2 emissions?," 0507 2015. [Online]. Available: https://skepticalscience.com/human-co2-smaller-than-natural-emissions.htm. [Accessed 2312 2019].

[5] "Science Controversies Past and Present," 0110 2011. [Online]. Available: https://physicstoday.scitation.org/doi/10.1063/PT.3.1295. [Accessed 2312 2019].

[6] A. Majda, Introduction to PDEs and Waves for the Atmosphere and Ocean, New York: Courant Institute of Mathematical Sciences, 2003.

[7] F. Bacon, The Advancement of Learning, London: Henrie Tomes, 1605.

[8] Scientific American, "CO2 Emissions Will Break," 0412 2019. [Online]. Available: https://www.scientificamerican.com/article/co2-emissions-will-break-another-record-in-2019/. [Accessed 23122019 ].

[9] State of Global Air 2019: Air pollution a significant risk factor worldwide, "State of Global Air 2019: Air pollution a significant risk factor worldwide," 06 2019. [Online]. Available: https://www.healtheffects.org/announcements/stateglobal-air-2019-air-pollution-significant-risk-factor-worldwide. [Accessed 2312 2019].

[10] P. Francisco, Laudato Si’, Bogotá: San Pablo, 2015. 
[11] R. G. Torres, "HIGH EFFICIENCY DEVICE TO CUT GASSES EMISSIONS FROM MOBILE SOURCES," in RTESE'17, Toronto, 2017.

[12] R. G. Torres, "AN EXPERIMENTAL EVIDENCE OF GASOLINE IONIZATION BY A MAGNETIC FIELD," in RTESE'18, NIAGARA FALLS, 2018.

[13] R. G. Torres, "CRITERIA FOR DESIGNING, BUILDING AND INSTALLING A MAGNETIC MINIMIZER," in RTESE'18, NIAGARA FALLS, 2018.

[14] WHO, "What Is Air Pollution ?," WHO Regional Office For South East Asia, New Delhi, 2018.

[15] Policy Exchange, "Driving Down Emissions," Policy Exchange, Londres, 2016.

[16] Occupational And Environmental Medicine. , "Locally Derived Traffic-related Air Pollution And Fetal Growth Restriction," ResearchGate, Berlin, 2012.

[17] P. Wright, "Air Pollution, Climate Change Among WHO's 10 Threats to Global Health in 2019," The weather Company, 22 January 2019. [Online]. Available: https://weather.com/science/environment/news/2019-01-22-whopollution-climate-change-10-threats-global-health. [Accessed 02 February 2019].

[18] WHO, "World Health Organization releases new global air pollution data," WHO News \& Media, 02 May 2018. [Online]. Available: http://www.ccacoalition.org/en/news/world-health-organization-releases-new-global-airpollution-data. [Accessed 13 January 2019].

[19] WHO Regional Office for Europe, "Health Effects of Transport- Related Air Pollution:Summary For Policy Makers," 2005. [Online]. Available: http://www.euro.who.int/_data/assets/pdf_file/0007/74716/e86650sum.pdf. [Accessed 16 January 2020].

[20] European Comision, "Green Vehicles," 30 April 2018. [Online]. Available: https://ec.europa.eu/inea/sites/inea/files/green_vehicles_brochure_2018.pdf. [Accessed 14 January 2020].

[21] NOOA, "Global Climate Report - May 2018 | State of the Climate | National," NOOA Report, 30 May 2018. [Online]. Available: https://www.ncdc.noaa.gov/sotc/global/201805. [Accessed 30 January 2019].

[22] Bloomberg, "For 400 Months in a Row, the Earth Has Been Warmer Than 20th Century Average," Bloomberg, 17 May 2018. [Online]. Available: https://www.bloomberg.com/news/articles/2018-05-17/april-was-400th-consecutivemonth-world-warmer-than-20th-century. [Accessed 30 January 2018].

[23] EPA, "How Mobile Source Pollution Affects Your Health," EPA, 15 December 2016. [Online]. Available: https://www.epa.gov/mobile-source-pollution/how-mobile-source-pollution-affects-your-health. [Accessed 30 January 2019].

[24] I. B. a. J. K. Neal Hickey, Air Pollution from Mobile Sources: Formation and Effects and Abatement Strategies, Cagliari: Springer Science+Business Media, 2014.

[25] EPA, "Criteria Air Pollutants," EPA, 8 March 2018. [Online]. Available: https://www.epa.gov/criteria-air-pollutants. [Accessed 30 January 2019].

[26] EPA, "Overview of Greenhouse Gases: Carbon Dioxide Emissions," EPA, 4 June 2018. [Online]. Available: https://www.epa.gov/ghgemissions/overview-greenhouse-gases. [Accessed 29 January 2019].

[27] EPA, "Global Greenhouse Gas Emissions Data," EPA, 13 April 2017. [Online]. Available: https://www.epa.gov/ghgemissions/global-greenhouse-gas-emissions-data. [Accessed 28 January 2019].

[28] G. Santos, Road transport and CO2emissions: What are the challenges?, Cardiff: Published by Elsevier Ltd, 2017.

[29] D. S. James Binney, The Physics of Quantum Mechanics, vol. Vol 13, Oxford: Cappella Archive, 2011, pp. 181-200.

[30] Mitsubishi Chemical Advanced Materials, "Tivar1000 Product Data Sheet," 01 April 2019.

[Online].Available:https://www.mcam.com/fileadmin/quadrant/documents/QEPP/EU/Product_Data_Sheets_PDF/PE/ TIVAR_1000_PDS_E_02052019.pdf. [Accessed 1003 2020]. 
145-10 